\title{
EL CONCEPTO JURÍDICO DE PERSONA Y LOS ESTATUS TUTELADOS. EL CASO DEL CONSUMIDOR Y DEL ADHERENTE EN EL DERECHO ECONÓMICO ARGENTINO
}

\section{THE LEGAL CONCEPT OF PERSONA AND THE PROTECTED STATUSES. CONSUMERS AND ADHERENTS CASE IN ARGENTINE ECONOMIC LAW}

\author{
Helga María Lell \\ Docente \\ Facultad de Ciencias Económicas de la UNLPam \\ hlell@ius.austral.edu.ar \\ Argentina, La Pampa
}

\section{SUMARIO}

- Introducción.

- La metáfora y los estatus.

- La tutela de la persona en el derecho económico.

- El consumidor y el adherente como estatus.

- La jerarquía constitucional del rol de consumidor.

- Regulación de los estatus del consumidor y de adherente.

- Partes de interpretación tutelares del adherente.

- Relación de consumo.

- Interpretación a favor de los consumidores.

- Consideraciones finales.

\section{RESUMEN}

Este artículo parte de cómo el derecho conceptualiza a la persona como un ente que juega roles en el escenario jurídico a partir de una metáfora que lo vincula con las antiguas máscaras teatrales. Esta concepción, en el ordenamiento jurídico argentino, está ligada a ciertas notas de la esencia humana como son la inviolabilidad, la dignidad y la autonomía. En ese marco, en el paradigma actual, la persona se entiende especialmente a partir de roles con el fin de tutelar de la mejor manera posible el goce y ejercicio de los derechos. Esto conlleva que en el derecho económico se tutelen de manera particular ciertos sujetos con el fin de igualarlos respecto de la parte más fuerte en la relación jurídica. De esta manera, aquí se aborda el derecho de los consumidores/ usuarios y de los adherentes como categorías selectas por el derecho para proteger. El cuidado jurídico especial de estos roles se expresa a través de cláusulas interpretativas que alteran el tradicional derecho contractual y también el paradigma de la autonomía e igualdad de las partes no solo como punto de partida (dar por sentado que el consumidor y el adherente son más débiles que sus cocontratantes) sino también como punto de llegada (se empodera al consumidor y al adherente objetivamente considerados sin que su contraparte reciba un trato especial).

El objetivo del artículo es mostrar cómo se ha dado el retorno de los estatus como forma de tutelas especiales en el derecho económico a través de las relaciones de consumo.

\begin{abstract}
This article departs from the legal concept of person as a being that plays different roles in the legal scene. This idea comes from a metaphor that remembers the antique masks on the Latin and Greek theatres. In Argentinian legal system, the concept of person cannot be understood without the characteristics of dignity, autonomous and being inviolable. In
\end{abstract}


this context, in nowadays paradigm, person is understood specially from different roles in order to protect in the best possible way concreting rights. That leads to the fact that in economic right some individuals get special attention and special regulations in order to be more equal to the strongest part in the relationship. According to this, this paper will focus on the consumers/users and adherent's roles. Legal protection is expressed through interpretative statements that change contractual law as it is usually conceived. It takes for granted that both parts in a contract are not equals but also treats differently those parts.

The aim of the article is to show how the return of statuses has become a protective legal tool in the case of economic law in Argentinian legal system in consumer's relationships.

\section{PALABRAS CLAVE}

estatus; consumidor; contratos de adhesión; persona

\section{KEYWORDS}

adhesion contracts; consumers; Person; statuses

\section{INTRODUCCIÓN}

En el derecho, el concepto de persona se define por ser un centro de imputación normativa. Esta definición proviene de una antigua metáfora teatral y apunta que el ser humano no es relevante como tal en clave jurídica, sino que lo es a partir de los roles que juega conforme a los derechos y obligaciones que el ordenamiento jurídico le otorga. La definición jurídica de persona antedicha ha provocado múltiples debates en el marco de la teoría del derecho respecto de si implica o no desconocer la existencia de ciertos derechos como previos o inherentes al ser humano. No obstante, en este trabajo consideraré un tanto resuelta esta cuestión, al menos desde la perspectiva legal, en el sistema jurídico argentino ya que allí se ha optado por tomar como referencia de la interpretación de las normas y relaciones jurídicas ciertas notas propias de la esencia humana como son la dignidad, la inviolabilidad y la autonomía.
Los resultados de la interpretación antedicha se hacen evidentes justamente a la hora de considerar los estatus que ocupa un ser humano frente al derecho y al momento de determinar qué puede o no el derecho hacer con él.

Este trabajo parte del estudio del concepto jurídico de persona en el ordenamiento argentino como un espacio de atribución de roles determinados por el campo normativo, pero fuertemente condicionado por el reconocimiento de un sujeto humano que opera como principio interpretativo. En este marco, me centraré en dos estatus en particular que surgen en el marco del derecho económico, esto es, caracterizado por su contenido patrimonial y que generan una tutela especial. Estos estatus son el de consumidor/ usuario y adherente. Ello, con el fin de mostrar lo que Viola (2015) denomina el retorno de los estatus y que desnivela la forma de concebir la conquista propia de la modernidad de concebir a los individuos como libres e iguales a la hora de atribuir derechos y obligaciones.

\section{LA METÁFORA Y LOS ESTATUS}

La noción de persona llega al ámbito jurídico desde una antigua metáfora. En la teorización sobre el derecho romano (no en el derecho romano en sí), se ha utilizado este término para denominar a los sujetos a quienes se les imputaban derechos y obligaciones. Así, estos podían ser seres humanos o ficciones, aunque no existen desarrollos avanzados de una concepción de la persona jurídica. Sí podría afirmarse que existe alguna idea de ello a partir de la diferencia entre el mero homo y algunas abstracciones ${ }^{1}$.

La metáfora parte de reconocer un elemento del teatro: la máscara, llamada persona ${ }^{2}$, que

\footnotetext{
1 Entre las respectivas abstracciones, Di Pietro y Lapieza Elli (1985) menciona al populus romanus, al fiscus, el municipium, etc. En un estudio respecto de instituciones de la época clásica, Blanch Nogués (2007) explica las dificultades de utilizar la categoria de persona jurídica para analizar el derecho romano. No obstante, señala que esta idea puede ser útil en un sentido instrumental y no ontológico ya que permite entender cómo ciertas entidades actuaban como sujetos de derecho.

2 En la antigua Grecia, la respectiva máscara se denominaba "prósopon", que significa persona y de hecho se encuentra hoy en día en el art- XX del Código Civil griego. Curiosamante, este término no hace hincapié en la audición de la voz sino en cómo el rostro aparece ante la mirada de otro. Por otro lado, hay que aclarar que es posible que tanto prósopon como personae deriven del etrusco phersu. Sobre las raíces etimológicas ver Corominas, 1981; Paricio, 2015, Stoddart, 2009; Liddell y Scott, 1940; Néndoncelle, 1948, Chantraine, 1974; Ernout y Meillet, 2001.
} 
y del adherente en el derecho económico argentino

The legal concept of persona and the protected statuses. Consumers and

adherents case in argentine economic law

utilizaban los actores en escena para representar su papel y que, también, les permitía hacer más audible su voz. A partir de esta idea, se intenta revelar que, en el campo jurídico, el ser humano interpretaba roles según su estatus libertatis (si era un hombre libre o esclavo), civitatis ( $\mathrm{si}$ era ciudadano romano, latino o peregrino) y familiae (si era sui iuris o alieni iuris) (Petit, 2015).

Viola (2015) expone que desde aquella antigua concepción a la actualidad han existido múltiples transformaciones que van desde la substancialización (por ejemplo con Boecio ${ }^{3}$ ) a la consideración del hombre como sujeto de derechos en la modernidad ${ }^{4}$ y como sujeto a proteger de la actualidad. Es en la tutela de las situaciones contextuales y personales en las que todos los individuos pueden encontrarse en algún momento su vida que el jurista italiano encuentra la solidificación de los estatus. Ya no se trata de pensar al ser humano como categoría abstracta sino a partir de su existencia misma, en función de su género, edad, ciudadanía, orientación sexual, de su estado de salud, de si es consumidor o usuario. Los estatus ya no se utilizan para conceptualizar a la persona a partir de permitirle o impedirle interpretar ciertos roles, sino que han retornado para ser una herramienta de protección eficaz en función de los roles que juega el individuo en sociedades complejas, particularmente desde la perspectiva económica.

No obstante, lo expuesto en último término, cabe destacar que la interpretación de la metáfora no es pacífica. La noción de persona como ente susceptible de adquirir derechos $\mathrm{y}$ obligaciones ha sido un terreno de disputas. Para el positivismo jurídico más extremo, en el plano teórico, la respectiva definición ha sido útil para fundamentar la erradicación del reconocimiento de derechos naturales o humanos más allá de los reconocidos normativamente. La exposición más paradigmática de este punto puede encontrarse en la Teoría pura del Derecho de Kelsen (1982) quien, al abordar el sujeto de derecho

\footnotetext{
3 Por ejemplo, Boecio dice en De Duabus naturis et una personaChristi; PL 64, 1343, "Persona est naturae rationalis individua substantia".

4 Uno de los principales cambios entre la Edad Media y el Renacimiento fue el cambio del eje respecto del fundamento de los derechos naturales que dejaron de tener un basamento teológico para considerar al sujeto racional como portador innato de derechos tales como la vida, la libertad, la propiedad, etc. Precisamente, todos los seres racionales son iguales en virtud de su razón. El paradigma que acompaña estas instancias es el del contractualismo político.
}

como tópico explica que toda persona es persona jurídica $\mathrm{y}$, por lo tanto, la respectiva adjetivación es una redundancia. Esta postura deriva en que no existan más derechos que los que el ordenamiento jurídico reconoce. El mayor riesgo es que esta desvinculación de todo contenido moral (cuya presencia es, en todo caso, contingente) otorga una gran omnipotencia al Estado a la par que deja impotentes a los individuos. El jusnaturalismo ${ }^{5}$, no reniega de la utilidad de esta definición pero no reconoce que pueda avasallarse al ser humano, es decir, no cualquier contenido normativo es posible sino que debe respetarse el derecho natural. Allí es donde puede encontrarse la mayor asimetría.

La tensión aquí, como puede verse, radica no solo en dos posturas jusfilosóficas distintas sino también en una tensión entre lo humano y lo jurídico. Por otro lado, entra en juego el cuestionamiento respecto de cómo el campo normativo se relaciona con la realidad ${ }^{6}$.

En la introducción he señalado que esta tensión se encuentra resuelta en el ordenamiento jurídico argentino. Me detendré brevemente a explicar esta afirmación.

El primer Código Civil de la República Argentina (en adelante, CC) fue sancionado, mediante la ley $\mathrm{N}^{\circ} 340$, el 25 de septiembre de 1869 y promulgado cuatro días más tarde, durante la presidencia de Domingo Faustino Sarmiento. La redacción del proyecto estuvo a cargo de Dalmacio Vélez Sarsfield quien siguió una tendencia liberal individualista ${ }^{7}$ y tomó como principales fuentes al Código Civil francés, al Código Civil de Chile y al Esbozo de Código Civil para Brasil elaborado por Freitas, entre otras. También se inspiró en estudios sobre derecho romano. La votación en

$5 \mathrm{Si}$ bien aquí se menciona al jusnaturalismo como una categoría uniforme, esto es solo a los efectos prácticos. Hay que aclarar que existen múltiples corrientes jusnaturalistas cuyo común denominador es sostener que existe un derecho más allá del derecho positivo y que es obligatorio. Las diferencias entre las posturas son variadas y responden a la fuente del derecho natural (cosmológica, teológica, racional, axiológica, antropolótica, etc.), al carácter del derecho natural en relación con el derecho positivo (si una ley injusta es o no obligatoria, si es considerada o no juridica, si existe o no derecho a la desobediencia), entre otras.

6 La contraposición y los problemas semánticos sobre la referencialidad del signo lingüístico persona han sido tratados en Lell, 2017. Para ampliar, alli se remite.

7 Al respecto existen algunas controversias. No obstante, en mayor o menor grado, es innegable la inspiración liberal del Código Civil. Un artículo que sintetiza brevemente el debate con relación a las fuentes de la norma se puede encontrar en Arias (1969). 
el Congreso fue a libro cerrado y, por lo tanto, no hubo modificaciones. En dicha norma, el Título I, denominado "De las personas jurídicas", comenzaba con la siguiente definición: "son personas todos los entes susceptibles de adquirir derechos, o contraer obligaciones" (artículo 30). Luego, clasificaba a las personas en dos grupos: de existencia visible y de existencia ideal. Las primeras no tenían una definición y estas últimas abarcaban a aquellas que no fueran de existencia visible ${ }^{8}$.

Como puede notarse, la definición es la clásica de la teoría jurídica y que, además, es fácilmente vinculable con el positivismo jurídico. No obstante, como se ha mencionado, esta definición tampoco es necesariamente ajena a las corrientes jusnaturalistas. De esta manera, este artículo daba lugar a múltiples interpretaciones. En la práctica, los operadores jurídicos han sostenido que el hombre es el centro del ordenamiento jurídico ${ }^{9} \mathrm{y}$ también se ha usado un tanto indistintamente el término "persona" respecto de ser humano ${ }^{10}$.

Por su parte, el Código Comercial (en adelante, CCom) fue redactado por Eduardo Acevedo y Dalmacio Vélez Sarsfield en 1858 y fue sancionado en 1859 para la provincia de Buenos Aires que, en ese entonces, se encontraba separada de la Confederación Argentina. En 1862 , tras la reunificación nacional, por ley $\mathrm{n}^{\circ}$ 15 , este Código rigió para todo el país. Esta norma regula los actos de los comerciantes (definidos como aquellos quienes hacen del comercio su profesión habitual) y también los actos de comercio (lo cual implicaba regular la actividad de un no comerciante que realizara un acto de comercio y cuya contraparte fuera un comerciante) $)^{11}$. De acuerdo a lo que se ha explicado, podemos ver que el derecho comercial pone el acento notablemente en el ejercicio de un rol jurídico: el del comerciante, en el caso de la mirada subjetiva, y el de quien realiza un acto de comercio sin ser comerciante, desde la mirada objetiva. El derecho comercial

$8 \mathrm{El}$ artículo $32 \mathrm{CC}$ señalaba: "Todos los entes susceptibles de adquirir derechos, o contraer obligaciones, que no son personas de existencia visible, son personas de existencia ideal, o personas jurídicas".

9 Por ejemplo, así lo ha dicho la Corte Suprema de Justicia de la Nación en el caso "Bahamondez, Marcelo s/ medida cautelar". CSJN, 06/04/1993.

10 Ejemplo de ello son los tratados internacionales de derechos humanos y también diversos códigos civiles latinoamericanos. Este tema ha sido abordado en Lell, 2018.

11 En los artículos 1 a 8 CCom se especifica esta circunstancia y se define a los comerciantes, por un lado, y a los actos de comercio, por el otro. no es aplicable al individuo como tal sino en cuanto aparece dentro de la escena comercial.

En 2011, la presidente de la Nación argentina, Cristina Fernández de Kirchner, designó, mediante el decreto $\mathrm{N}^{\circ} 191 / 11$, una comisión de juristas para redactar un proyecto de Código Civil y Comercial (en adelante, $\mathrm{CCyC}$ ), es decir, una norma que unificara ambas legislaciones. El nuevo Código fue sancionado el 1 de octubre de 2014, mediante ley $\mathrm{N}^{\circ} 26994$, y promulgado el 7 del mismo mes. Entró en vigencia el 1 de agosto de $2015 \mathrm{y}$, desde entonces, han quedado derogados el Código Civil y el Código de Comercio que habían regido hasta entonces.

Esta nueva norma prescinde de una definición genérica de persona y contempla dos categorías: la humana y la jurídica. Respecto de la primera, tampoco explica en qué consiste aunque sí menciona que comienza con la concepción (artículo $19 \mathrm{CCyC}$ ) y reconoce dos características: su inviolabilidad y dignidad (artículo $51 \mathrm{CCyC})^{12}$. Por su parte, las personas jurídicas sí son definidas: "Son personas jurídicas todos los entes a los cuales el ordenamiento jurídico les confiere aptitud para adquirir derechos y contraer obligaciones para el cumplimiento de su objeto y los fines de su creación" (artículo 141 CCyC).

El contraste entre la situación de las personas humanas y la de las personas jurídicas permite ver que la tensión entre una mera creación legal que queda a merced del ordenamiento jurídico y el individuo de carne y hueso recipiendario de las obligaciones y derechos, queda resuelta en el caso argentino. Existe una persona humana a la cual no se le puede imputar cualquier contenido, sino que este debe respetar la dignidad y la inviolabilidad.

\section{LA TUTELA DE LA PERSONA EN EL DERECHO ECONÓMICO}

Anteriormente, he señalado que Viola (2015) comenta que en la modernidad el individuo era un sujeto de Derechos ${ }^{13}$ pero que en la

12 Creo, además, que es posible sostener que reconoce la autonomía de la persona humana. Esta característica no se encuentra en el artículado relativo a la persona humana pero sí más adelante cuando se señala el deber de indemnizar a alguien cuando se ha dañado su plan de vida (artículo 1738 CCyC). En virtud del lugar que se le da al proyecto vital, se puede considerar que el CCyC da por presupuesta esta nota que es el fundamento de la exigibilidad del respectivo resarcimiento.

13 Para entender mejor esta categoria, se puede caracterizar al individuo con una libertad negativa, en el sentido que 
y del adherente en el derecho económico argentino

The legal concept of persona and the protected statuses. Consumers and adherents case in argentine economic law

época contemporánea este es un sujeto a proteger, es decir, no se espera ya que el Estado simplemente se abstenga de avasallar al individuo universalmente considerado sino que se enfatiza en tutelas especiales conforme a la misma existencia contextualizada. Esto rompe con el principio de igualdad entre hombres ya que ahora, según el estatus ostentado se puede recibir una especial protección. La desigualdad deviene de que no todo estatus amerita protección. La igualdad presupone la autonomía en la toma de decisiones y, por ende, la capacidad del individuo para afrontar las consecuencias de sus actos. No obstante, la consideración de una parte como más débil y a proteger, de proponer al Estado como garante activo para superar la debilidad, da por sentado que los contratantes no son iguales, que uno de ellos amerita cuidado y que el restante no debería obtener la ventaja que obtendría de no intervenir una institución pública.

Cómo seleccionar las categorías a tutelar resulta un problema en sí mismo puesto que estas siempre son abstractas y genéricas, prescinden de los detalles individuales y de otras categorías que entran en intersección. Toda vivencia problemática es particular y por lo tanto resulta dificultoso resolverla desde un plano genérico. Por ejemplo, la categoría de "mujer" es muy amplia ya que puede ser vivida a partir de otras clases: pobre, indígena, desempleada, madre, ejecutiva, enferma, con estudios universitarios, propietaria, religiosa, etc. A pesar de este inconveniente, el derecho opera con clases genéricas como herramienta objetiva para distinguir $\mathrm{y}$, al mismo tiempo, mantener en la mayor medida posible la igualdad. Por otro lado, la clasificación abstracta colabora en no caer en un relativismo total.

En el marco del derecho económico, se dan múltiples relaciones. Cada una de ellas, da lugar a respectivos roles según las obligaciones y los derechos establecidos. En las relaciones económicas, al menos en un sistema democrático y capitalista, los individuos pactan voluntariamente entre sí. Esta idea, presentada de manera simplista, amerita ser complejizada.

Las relaciones económicas entre individuos, esto es, en las cuales el patrimonio se

Berlin (1969) le da a esta expresión, o con la libertad de los modernos, como la califica Constant (1849). Estas dos libertades no son equivalentes entre si, aunque creo que la conjunción puede arrojar luz sobre la idea del individuo como sujeto de derechos. ve involucrado, presuponen un esquema de igualdad entre las partes que pactan. Supongamos que el Sr. Sigma tiene una casa pequeña que no habita porque su familia es numerosa y que desea alquilar para obtener a cambio un precio que le ayudará a pagar el alquiler de su actual vivienda. El Señor Rau no tiene una casa y desea alquilar la casa de Sigma. Ambos negocian las cláusulas, acuerdan un precio y se hacen responsables por el cumplimiento y el incumplimiento del contrato. Hasta aquí, podemos ver el paradigma de la igualdad: ambas partes tienen algo que la restante necesita y ambas están dispuestas a negociar. Si alguna deja de cumplir, correrá con las consecuencias contractuales, administrativas y/o judiciales. En general, el sistema jurídico no interviene demasiado en estos contratos: suele dejar a criterio de las partes la duración (aunque se suele establecer una duración mínima), el precio, la jurisdicción judicial, si es o no posible subalquilar, tener o no mascotas, si se puede cambiar el color de las paredes, quién estará a cargo de las reparaciones, etc. Ahora bien, pensemos otro ejemplo: en una pequeña ciudad se instala una empresa muy importante. Muchas personas comienzan a mudarse allí por sus trabajos. No obstante, la ciudad no ha desarrollado el mercado inmobiliario y, por ello, las viviendas en alquiler son muy pocas. Al ser un bien escaso y aumentar la demanda, el precio se dispara exponencialmente. Supongamos que, comparativamente, el precio del alquiler del inmueble del Sr. Sigma se incrementa un $300 \%$ desde que la empresa se instala. El alquiler es prácticamente inaccesible pero las personas no quieren perder su trabajo y no pueden vivir en la calle. Así, quienes desean ser locatarios ven su libertad de negociación un tanto constreñida. Sigma sabe que tiene un bien codiciado y que tarde o temprano alquilará el inmueble al precio que desea y bajo las condiciones que quiere imponer ya que existe poca competencia. En ese marco, el contexto ha empoderado más a una parte que a la restante. Como puede notarse, se trata de los mismos bienes, del mismo tipo de contrato y hasta de los mismos sujetos en la primera y la segunda situación, pero se desnivela la capacidad de negociación. Ambos sujetos son autónomos, es decir, eligen libremente entrar en la relación contractual. Rau siempre puede rechazar el contrato $y$, si no consigue otra casa de su agrado, tiene la posibilidad de buscar 
un empleo en una ciudad más económica en términos de locación. Lo cierto es que la vida no funciona de esta manera, las personas tienden a ponderar elementos que complejizan la toma de decisiones y que constituyen ventajas y desventajas a la hora de emprender relaciones jurídicas. Quizás, un solo contrato no baste para cambiar radicalmente el curso de sus vidas y, por lo tanto, no son tan autónomos como pareciera en abstracto.

En ese marco, el sistema jurídico interviene al procurar nivelar a las partes que en un contrato podrían padecer el desequilibrio. $\mathrm{La}$ intervención tiene costos. Por un lado, quien nota el costo más rápidamente es la parte contratante que no es beneficiada por las medidas jurídicas, es decir, aquella que se considera más fuerte. Es fácil pensar que más fuerte hace referencia, por ejemplo, a un gran grupo económico. Sin embargo, cuando significa un ciudadano de a pie que simplemente se encuentra en una sencilla operación contractual, algunas situaciones pueden parecer no tan claras a la hora de calificar como justas o injustas algunas medidas de reparto. Por otro lado, los costos también se trasladan al resto de la ciudadanía, al menos cuando las políticas públicas requieren la inversión de recursos que, por supuesto, deben ser recaudados por el Estado. Volvamos al ejemplo anterior donde el Sr. Sigma alquila un inmueble a cambio de un alto precio en el marco de un mercado inmobiliario con alta demanda y escasa oferta. El Estado decide intervenir con una medida de largo plazo que hará bajar los precios de los alquileres: aumentar la oferta. Para ello, se desarrolla una doble estrategia: 1) se instala un sistema de trasporte gratuito desde un pueblo vecino en el cual el precio de los alquileres es más accesible. Los locatarios tienen que estar dispuestos a perder dos horas de su vida en traslados de un lugar a otro pero la diferencia económica ciertamente compensa este inconveniente; y 2) se inicia la construcción de barrios en la ciudad cuyo costo se encuentra a cargo del Estado y que luego se repartirán entre los interesados a cambio del pago de cuotas muy bajas, equivalentes a las de un alquiler razonable o incluso menores, por un lado, y se otorgan créditos con intereses a una tasa menor a las bancarias destinados a la construcción de viviendas. Como puede notarse, un sistema así solo es posible en un esquema sin fines de lucro, aunque para solventar una política de este tamaño, es necesario obtener el financiamiento de las arcas públicas. Estas, a su vez, se conforman a través de, principalmente, la carga impositiva. Por este motivo, el mismo Sr. Sigma, por ejemplo, perjudicado por las políticas de transporte y de crédito, aporta, al pagar impuestos, al desarrollo de ellas.

Este ejemplo sirve para ilustrar una consecuencia económica de la interpretación de los derechos tutelares: el costo que beneficia a un grupo es solventado por la sociedad o, al menos, por parte de ella. Entre los aportantes puede estar el mismo beneficiado, pero también quien puede ser perjudicado por las medidas a solventar. Por supuesto, también se involucran terceros que no son parte de las relaciones jurídicas de base.

En las páginas que continúan, me detendré en algunas instituciones tutelares propias del ordenamiento jurídico argentino, más específicamente, en el derecho civil y comercial en lo que respecta a las relaciones económicas. Ello, con el fin de observar cómo influye el concepto jurídico de persona como inviolable, con dignidad y autonomía en el marco de los vínculos jurídicos con contenido patrimonial.

\section{EL CONSUMIDOR Y EL ADHERENTE COMO ESTATUS}

Uno de los estatus que tutela el derecho económico en particular es el del consumidor, esto es, el de la persona que, en el marco de una relación de consumo, adquiere de otra un producto o servicio, no para trasladarlo hacia otras manos, sino para consumirlo o utilizarlo -valga la redundancia-. En dicha relación se produce un intercambio (aun cuando la relación sea a título gratuito) y, por ende, nacen obligaciones y derechos. El especial cuidado que la regulación jurídica tiene para con el consumidor cualifica la relación de intercambio que deja de dar lugar a obligaciones y derechos como lo haría en el paradigma normal para aumentar la carga del sujeto proveedor y los derechos del consumidor.

A pesar de que el consumo y los consumidores han existido históricamente, el derecho del consumidor, como rama de la disciplina jurídica, es relativamente reciente y nace a partir de una distinción que toma como criterio el poder de negociación de las partes (Alpa, 2004). Algunas veces, todos los intervinientes tienen igual poder de negociación para incluir 
y del adherente en el derecho económico argentino

The legal concept of persona and the protected statuses. Consumers and adherents case in argentine economic law

cláusulas en un contrato (de allí que se los pueda llamar contratos paritarios), es decir, se discute el contenido para llegar a un acuerdo (Lorenzetti, 2003). Ambas partes dialogan, negocian y construyen un trato de manera conjunta. En otras palabras, las dos partes tienen una igual cantidad de voluntad y de poder negociar en pos de concretar sus expectativas. Ambos saben qué es lo que quieren, cómo ordenan sus prioridades y qué están dispuestos a resignar para lograr su objetivo.

En materia contractual, la autonomía es el principio general ${ }^{14}$. Lo que las partes determinan y pactan es lo que rige la relación, excepto que la ley disponga lo contrario con algún fundamento relevante, por ejemplo, cuando una cláusula puede contrariar el orden público o afectar la dignidad o inviolabilidad de las personas (por ejemplo, no podría alguien venderse como esclavo, pactar una mutilación o vender un órgano propio ${ }^{15}$ ).

En contraste con la situación anterior y a la luz de los ejemplos expuestos anteriormente, en otras ocasiones, una parte puede imponer a la otra las pautas que rigen la relación jurídica. Ambas partes tienen voluntad, es decir, pretenden obtener algo de la relación que entablan. No obstante, en virtud de condiciones contextuales, una parte tiene mayor poder para negociar que la restante. Así, la contraparte, tiene menos poder para poder peticionar $o$ negociar por lo que la relación de asimetría se acentúa enormemente. Hay casos en los que la situación es aún peor que la ejemplificada. Una parte no consiente, sino que, más bien asiente. No hay un consentimiento propiamente dicho ya que la parte más débil no ha negociado nada. Solo le resta adherir (de allí, la denominación de contratos de adhesión).

$14 \mathrm{El}$ artículo $957 \mathrm{CCyC}$, define al contrato como "el acto jurídico mediante el cual dos o más partes manifiestan su consentimiento para crear, regular, modificar, transferir o extinguir relaciones juridicas patrimoniales", es decir, este no puede existir sin la manifestación de la voluntad. Por su parte, el art. 958 CCyC menciona: "Las partes son libres para celebrar un contrato y determinar su contenido, dentro de los limites impuestos por la ley, el orden público, la moral y las buenas costumbres".

$15 \mathrm{El}$ artículo $55 \mathrm{CCyC}$ señala: "El consentimiento para la disposición de los derechos personalísimos es admitido si no es contrario a la ley, la moral o las buenas costumbres. Este consentimiento no se presume, es de interpretación restrictiva, y libremente revocable" y el art. $56 \mathrm{CCyC}$ prohíbe "los actos de disposición del propio cuerpo que ocasionen una disminución permanente de su integridad o resulten contrarios a la ley, la moral o las buenas costumbres, excepto que sean requeridos para el mejoramiento de la salud de la persona, y excepcionalmente de otra persona, de conformidad a lo dispuesto en el ordenamiento jurídico. (...)”
Supongamos que Beta desea alquilar un departamento. El dueño, Alfa, propone un precio que a Beta le parece elevado. Beta hace una contrapropuesta que Alfa le parece muy baja. Acuerdan un precio intermedio. Además, el dueño no quiere que tenga mascotas porque los ladridos de un perro o los maullidos de un gato pueden ser molestos para los vecinos. No obstante, Beta tiene un pequeño pez que no produce ninguna molestia. Entonces, negocian que el término mascotas de la cláusula prohibitiva no incluye peces. Por otro lado, a Beta le gusta tocar la guitarra, pero el dueño quiere evitar la música a cualquier hora. Por ende, se pactan los horarios en los que se puede tocar un instrumento musical. Así sucesivamente con cada aspecto de interés. Claramente este es un contrato en el que las partes se sientan a negociar y consensuar. Las dos quieren algo y están dispuestas a resignar algo a cambio. Hay una jerarquización de expectativas respecto de las prestaciones y contraprestaciones. Ambas partes llegan a un acuerdo de voluntades con un poder igual de negociación (si a mí no me gustan las cláusulas de la contraparte o si alguna de ellas contraría un interés que no estoy dispuesta a resignar, puedo buscar otro departamento $\mathrm{y}$, si al dueño no le gustan mis propuestas, puede buscar otro inquilino).

Esto no siempre sucede así. Hay casos en los que una de las partes es sustancialmente más débil que la otra. Supongamos ahora que Gamma quiere contratar un servicio de telefonía celular. No tiene muchas opciones, solo hay tres compañías y todas tienen un servicio muy similar; de hecho, hay un acuerdo entre ellas sobre los precios mínimos a cobrar y las condiciones de coberturas son iguales ya que comparten las antenas. Gamma solicita a la primera de ellas dar de alta una línea. Rápidamente, el empleado del local, extiende un contrato impreso e indica dónde firmar. No se permite de ninguna manera discutir las cláusulas. Se puede elegir un plan u otro, pero son todas variantes redactadas antes de que Gamma se presentara a solicitar el servicio. Enojado, nuestro personaje se dirige a la segunda firma y a la tercera. En ambas sucede lo mismo. Solo puede adherir. No puede hacer ninguna propuesta. Si no desea alguna cláusula o si quiere agregar algo, no puede negociar. $\mathrm{O}$ se queda sin el servicio de telefonía celular o adquiere todo el paquete (incluyendo las cláusulas que me disgustan). Tiene el poder 
de elegir entre una oferta u otra, es decir, algún margen de libertad subsiste. El contrato continúa siendo tal ya que hay libertad, autonomía, pero esta se encuentra sumamente disminuida lo cual convierte al consumidor en la parte más débil y, por ende, a tutelar.

Para sintetizar: los contratos paritarios son aquellos en que las partes tienen un poder de negociación relativamente similar; en cambio, los contratos de adhesión son aquellos en que hay una parte dominante que impone el contenido del contrato y una parte débil que se limita a aceptarlo o rechazarlo.

Ahora bien, no todo se desarrolla en un contraste tan claro como el anterior. Hay contratos que podrían ser considerados paritarios en los cuales hay un desnivel entre las partes. Por ejemplo, si Delta adquiere un par de zapatillas tras negociar con total tranquilidad el precio, el material, el color y las condiciones de entrega, pero, luego, al utilizarlas resulta que adolecen de algún defecto (supongamos que la costura se deshace fácilmente). Quizás reclamar al vendedor no sea tan fácil ni práctico. Si él ha entregado el producto y Delta lo ha aceptado sin cuestionamientos, no parecieran existir buenos motivos para efectuar la devolución del dinero en forma total o parcial. Sin embargo, antes de utilizar las zapatillas no podía conocerse la resistencia de las costuras. El consumo del bien recibido es lo que muestra los defectos del contrato y no el contrato en sí mismo.

Veremos en las próximas páginas que las relaciones de consumo y el contrato de adhesión no son problemas iguales, pero se encuentran estrechamente relacionados. El consumidor/usuario y el adherente son estatus que revolucionan el derecho contractual pero que llegan a esta consecuencia desde el derecho de obligaciones, como la protección al deudor, a quien se presupone como la parte débil en las relaciones jurídicas (Lorenzetti, 2003).

El derecho del consumidor y del adherente, entonces, pretende proteger a las partes débiles en las relaciones de consumo y en un tipo especial de contratación que suele ser el origen de las relaciones de consumo. En la Argentina, las normas que dan lugar a esta rama se pueden encontrar en la Constitución Nacional, el Código Civil y Comercial y en la ley 24.240 (Ley de Defensa del Consumidor) ${ }^{16}$.

16 Sobre este entramado normativo, pueden consultarse Farina, 2004 y Garzino, 2005, quien comenta la normativa
Antes de adentrarme en dicha materia, hay que destacar un efecto que la concepción jurídica de la persona que se mencionó en las páginas anteriores tiene respecto del ámbito contractual: no todo contenido es posible. Algunas cláusulas no serían posibles, como, por ejemplo, un individuo no podría voluntariamente someterse a la esclavitud, tampoco, por lo tanto, otro sujeto podría ver satisfecha su voluntad como consumidor de tener un esclavo. La inviolabilidad del ser humano no permitiría que alguien pacte pagar mutilándose o pagar una deuda con un órgano. La dignidad no habilita que alguien acepte ser tratado en forma cruel o que las prestaciones de la contraparte no estén a la altura de su humanidad.

\section{La jerarquía constitucional del rol de consumidor}

La historia del Estado argentino, como tal, es decir, como nación independiente, encuentra sus inicios en la Revolución de Mayo acaecida en 1810. En ese entonces, el territorio pertenecía al Virreinato del Río de La Plata y, por lo tanto, era una colonia española. En aquel hito histórico, no se declaró la independencia sino la potestad de las Provincias del Río de La Plata de mantener la soberanía del Rey Fernando VII mientras este fuera mantenido cautivo por los franceses. Ello ocurrió en contra de la Junta Central de Sevilla que se había constituido en forma inconsulta respecto de los pueblos del territorio americano. La independencia se declaró finalmente seis años más tarde, en 1816. Desde ese entonces, existieron diferentes intentos constitucionales que fracasaron. Fue en 1853 cuando se dictó una Constitución Nacional que gozó de mediano consenso ${ }^{17}$.La Constitución Nacional argentina se encuentra vigente desde 1853 hasta el día de hoy con diversas modificaciones. El texto originario presenta una ideología marcadamente liberal. En 1957, una reforma incorporó los derechos sociales, aunque muchos de ellos no han sido concretados y, por lo tanto, han

previa al CCyC. Si bien estos trabajos se encuentran desactualizados en lo que al CCyC se refiere, tienen la virtud de lograr sintetizar los principales principios en la materia.

17 Se señala mediano dado que la provincia de Buenos Aires manifestó su disconformidad respecto de las disposiciones sobre la distribución federal de los impuestos aduaneros, que hasta ese entonces estaban a cargo de dicha provincia, donde radicaba el principal puerto. El conflicto llevó a su secesión, en 1852, de la Confederación Argentina y formación del Estado de Buenos Aires de hasta que, batallas bélicas mediante, retornó a la Argentina. Para ello, medió una modificación constitucional en 1860. 
y del adherente en el derecho económico argentino

The legal concept of persona and the protected statuses. Consumers and

adherents case in argentine economic law

resultado más bien declarativos (por ejemplo, la participación de los trabajadores en las ganancias de las empresas). La reforma más importante fue la acaecida en 1994. Si bien la convocatoria establecía que solo se reformaría la parte orgánica, esto es, la que regula la distribución de poderes y funciones del Estado, y se mantendría incólume la parte destinada a derechos y garantías, laAsamblea Constituyente consideró oportuno incluir algunas tutelas no contempladas en el texto constitucional. Por ello, creó una sección denominada "Nuevos derechos y garantías". De esta manera, salvó el escollo de incorporar derechos y garantías sin modificar la parte pertinente. En dicha sección se encuentran, en el artículo 42, desde 1994, los derechos del consumidor. Por lo tanto, a partir de aquella fecha, en el ordenamiento jurídico argentino, los estatus de consumidor y usuario ${ }^{18}$ gozan de jerarquía constitucional. En cuanto al contexto político, hay que destacar que durante la presidencia de Carlos Menem preponderó un modelo neoliberal de apertura económica, privatización de las empresas estatales y desregulación de los servicios. Esto tuvo un fuerte impacto en materia de servicios públicos por cuanto las prestaciones que otrora estuvieran a cargo del Estado pasaron a ser responsabilidad de privados. Los contratos se transfirieron automáticamente $\mathrm{y}$, junto con ellos, las cláusulas exorbitantes que caracterizan a los contratos del derecho administrativo. Por este motivo, las empresas privadas gozaron de ciertos privilegios en la prestación de servicios, como, por ejemplo, la cláusula solve et repete (para poder hacer un reclamo se debe pagar primero) y el monopolio del mercado en el ramo. La falta de competencia y el fuerte poderío, provocaron que no siempre las prestaciones fueran las más adecuadas. Al no existir libertad de elección u oferta, los consumidores y usuarios se vieron fuertemente afectados. En ese marco, se toma especial conciencia sobre la relevancia de la regulación tutelar en la materia.

El respectivo artículo $42 \mathrm{CN}^{19}$ señala:

18 En adelante, se utilizará el concepto de consumidor para considerar al usuario de bienes y servicios.

19 Este artículo tiene como fuente al artículo 51 de la Constitución de España de 1978 que señala: "Los poderes públicos garantizarán la defensa de los consumidores y usuarios, protegiendo mediante procedimientos eficaces, la seguridad, la salud y los legítimos intereses económicos de los mismos. 2) Los poderes públicos promoverán la información y la educación de los consumidores y usuarios, fomentarán sus organizaciones y oirán a éstas en las cuestiones que puedan afectar a aquéllos, en los términos que la ley establezca. 3) En el marco de lo dispuesto por los apartados anteriores, la ley regulará el comercio interior y el
Artículo 42.- Los consumidores y usuarios de bienes y servicios tienen derecho, en la relación de consumo, a la protección de su salud, seguridad e intereses económicos; a una información adecuada y veraz; a la libertad de elección, y a condiciones de trato equitativo y digno.

Las autoridades proveerán a la protección de esos derechos, a la educación para el consumo, a la defensa de la competencia contra toda forma de distorsión de los mercados, al control de los monopolios naturales y legales, al de la calidad y eficiencia de los servicios públicos, y a la constitución de asociaciones de consumidores y de usuarios.

La legislación establecerá procedimientos eficaces para la prevención y solución de conflictos, y los marcos regulatorios de los servicios públicos decompetencianacional, previendo la necesaria participación de las asociaciones de consumidores y usuarios $\mathrm{y}$ de las provincias interesadas, en los organismos de control.

Gelli (2011) señala que la incorporación de este artículo supone una modificación sustantiva en la visión constitucional ya que implicó una idea diferente de la persona humana, del rol del Estado y de la relación de ellos con las corporaciones. Esta autora explica que la concepción demoliberal de la constitución histórica se basaba en el derecho personal de propiedad (artículos 14 y $17 \mathrm{CN}$ ) $\mathrm{y}$, por ende, en la libertad contractual que se encuentra implícita. El Estado, en dicha visión debía garantizar a los habitantes el ejercicio del derecho de usar y disponer de su propiedad. Las únicas limitaciones estaban dadas por la cláusula para el progreso (artículo 75, inc. 18 $\mathrm{CN})$ que habilitaba el poder de policía para equilibrar el derecho de la propiedad y el bienestar general, cláusula que, además, fue frecuentemente utilizada durante las crisis económicas ${ }^{20}$. Respecto del consumidor, cabe destacar que sus derechos se pueden clasificar en dos grandes grupos: los patrimoniales y los personales. Como podrá vislumbrar el lector, este trabajo se dedica a los primeros que abarcan la protección de la libertad de elección,

régimen de autorización de productos comerciales".

20 Sobre la regulación del poder de policia en Argentina y sus usos en épocas de crisis ver Gordillo, 2013, Monge, 2017 y Durand, 2005. 
no sufrir daños en la relación de consumo, un trato digno y equitativo y la mayor protección cuando se sea la parte más débil.

Finalmente, en relación con los derechos del consumidor, la Constitución ha establecido la obligación del Estado de mantener un sistema capitalista de mercado con defensa de la competencia. La ley que ha regulado esto es la $\mathrm{N}^{\circ} 25156$ que tiende a combatir los abusos de posición dominante y toda tendencia monopólica. Como puede notarse, el sistema argentino intenta trasladar al usuario la potestad de decidir y, por ende, de aumentar la existencia de oferentes.

\section{REGULACIÓN DE LOS ESTATUS DE CONSUMIDOR Y DE ADHERENTE}

El Código Civil y Comercial argentino incorporó la categoría de contratos de adhesión no contemplada anteriormente. Como se ha mencionado anteriormente, el contrato de adhesión no se contrapone en absoluto a las relaciones de consumo, es decir, no cabe pensar en este par como un binomio que contrasta dos extremos y que, al darse uno, desaparece el restante. Ambas nociones están relacionadas por cuanto dan lugar una tutela especial a la parte que se considera más débil y con menor capacidad de negociación. Las relaciones de consumo apuntan más bien al vínculo entre dos partes, una proveedora y una consumidora a partir, no del momento de pactar sino del de destino del bien adquirido, esto es, su consumo. En cambio, los contratos de adhesión sí enfatizan en la forma de adquisición de los bienes y servicios, esto es, con la instancia de contratación (Cabrera Peña, 2011). Como ya puede vislumbrarse, para un consumidor, los problemas pueden presentarse en ambos momentos: a la hora de contratar y a la hora de consumir

El contrato de adhesión es definido en el artículo 984 CCyC como "aquel mediante el cual uno de los contratantes adhiere a cláusulas generales predispuestas unilateralmente, por la otra parte o por un tercero, sin que el adherente haya participado en su redacción".

Aquí tenemos, por un lado, el estatus de adherente como aquel que acepta cláusulas en cuya redacción no ha participado y el rol del redactor de las cláusulas que puede clasificarse en co-contratante o tercero respecto del contrato ${ }^{21}$.

\section{PAUTAS DE INTERPRETACIÓN TUTELARES DEL ADHERENTE}

La interpretación constituye uno de los procesos y resultados más relevantes del mundo jurídico. La legislación se encuentra redactada mediante palabras y se encuentra preparada para regir durante largos períodos. Esto implica que el sentido de los enunciados pueda variar y también que desaparezcan casos para los que la norma se encontraba pensada y que aparezcan otros no previstos. Por, sobre todo, la hermenéutica cobra relevancia en el fenómeno bajo análisis porque es la que concreta los derechos en juego y por lo tanto es a través del proceso interpretativo que se ponderan el principio de igualdad y autonomía, por un lado, y la tutela de los sujetos más débiles.

En el caso de un contrato de adhesión, el artículo $986 \mathrm{CCyC}$, distingue entre cláusulas generales y cláusulas particulares. A estas últimas las entiende como negociadas individualmente y que, por ello, pueden ampliar, limitar, suprimir o interpretar cláusulas generales (que, por sentido contrario, serían las predispuestas y no negociadas). En caso de incompatibilidad entre cláusulas generales y particulares, prevalecen estas últimas ya que son aquellas en las que se presume que habría participado la parte protegida.

También, en los contratos de adhesión, cuando una cláusula predispuesta sea ambigua, se debe interpretar en contra del co-contratante predisponente, es decir, del redactor (artículo 987). Es interesante la selección de palabras ya que no se estipula a favor del adherente sino en contra del predisponente. Esta última mención no necesariamente es tutelar de quien no ha participado de la redacción, aunque debería ser interpretada de esa manera. Por el contrario, habilitaría una suerte de sanción a quien debió cuidar la redacción, pero no asegura que la contraparte resulte beneficiada. El fundamento de esta disposición es que quien ha redactado los términos busca su mayor beneficio $\mathrm{y}$, por ende, si una estipulación no es certera, ya sea de manera intencional o por descuido, quien correría el mayor riesgo y quedaría sin seguridad jurídica sería la parte adherente. A

21 Esta última subclasificación respecto de quién es el redacto no parece relevante en cuanto a los efectos jurídicos. 
y del adherente en el derecho económico argentino

The legal concept of persona and the protected statuses. Consumers and

adherents case in argentine economic law

partir de este artículo, la parte más interesada en lograr precisión en las cláusulas será la redactora ya que de lo contrario, de antemano, no podría calcular cuál será el beneficio o perjuicio de una redacción ambigua.

El predisponente corre con la carga de poner a disposición del posible adherente de toda la información o documentación a la que haga referencia en las cláusulas de manera tal que la oferta sea autosuficiente. Si no lo hiciera, las cláusulas que hagan remisiones hacia documentos o elementos externos se tendrán por inexistentes (artículo $985 \mathrm{CCyC}$ ). Este principio interpretativo, como puede verse, permite tener como no escritos elementos que sí existen solo que no se encuentran adecuadamente conectados. Hay que señalar dos cuestiones un tanto complejas al respecto. Lo primero es cómo probar que el predisponente ha puesto a disposición del adherente la información ya que no necesariamente la información se puede dar por escrito. Por una cuestión probatoria, los contratantes intentarán dejar todo documentado, pero no siempre la textualidad impresa es la más clara. Esto nos lleva al segundo punto. La información o documentación debe ser adecuada conforme al nivel de la contraparte, algo que en un contrato predispuesto es casi imposible ya que no se adapta al co-contratante. De esta manera, este principio de la autosuficiencia es muy interesante en lo declarativo, pero puede resultar absolutamente obsoleto en la práctica. Al respecto, además, cabe recordar que la Constitución Nacional exige que la información sea adecuada. Por ende, la información y documentación anexa es tan solo un paso que no puede omitir la explicación respectiva.

Asimismo, se prohíben las cláusulas abusivas favorables al predisponente, entendidas estas como aquellas que desnaturalizan las obligaciones del predisponente, amplían sus derechos resultantes de normas supletorias, importan la restricción o la renuncia de derechos del adherente, o que no son razonablemente previsibles. En caso de existir, se tienen por no escritas (artículo $988 \mathrm{CCyC}$ ).

Finalmente, de manera contraria a lo que rige en el resto de la rama contractual donde la manifestación de la voluntad de manera literal es lo que regula la relación entre las partes como medio para mantener incólume la seguridad jurídica, en los contratos de adhesión se prohíbe la interpretación literal de los términos utilizados al manifestar la voluntad (artículo 1062). Ello tiene sentido por cuanto se entiende que una de las partes no ha podido participar activamente de la redacción y, por lo tanto, la literalidad no le pertenece.

Los contratos de adhesión son los casos más claros en los cuales el proveedor puede manifestar su mayor poderío sobre el consumidor. No obstante, también este poder mayor puede encontrarse en contratos de consumo paritarios.

\section{RELACIÓN DE CONSUMO}

Hemos mencionado que la persona aparece ante la escena jurídica por su estatus, esto es, por el rol que juega en una relación. La relación de consumo, según el artículo $1092 \mathrm{CCyC}$, es un vínculo entre un proveedor y un consumidor. Allí aparecen, entonces, los dos papeles interpretados. El consumidor o el usuario es toda persona humana o jurídica que adquiere o utiliza bienes o servicios en forma gratuita $\mathrm{u}$ onerosa como destinatario final en beneficio propio o de su grupo familiar o social (artículo 1 , ley $\mathrm{N}^{\circ}$ 24240). Hay que resaltar que para ser considerado consumidor o usuario no solo se debe participar en la relación de consumo, sino que no se debe ser un intermediario en la compraventa de bienes o prestación de servicios. Es decir, la característica viene dada con el nombre mismo del rol: ser quien consume o quien utiliza finalmente el objeto de la relación.

La ley $\mathrm{N}^{\circ}$ 24240, denominada Defensa del Consumidor, y el Código Civil y Comercial equiparan al consumidor a los terceros beneficiarios y a los terceros expuestos y les permiten invocar la protección del consumidor como si fuesen consumidores.

El tercero beneficiario es aquel que, sin ser parte de una relación de consumo, como consecuencia o en ocasión de ella, adquiere o utiliza bienes o servicios como destinatario final. Es decir, aquella persona que se beneficia de una relación de consumo sin ser jurídicamente parte de ella. Por ejemplo, un empleado que es asegurado por una empresa aseguradora contra riesgos de trabajo. Quienes contratan son la respectiva aseguradora y el empleador. El beneficiario mediato o final es el trabajador que no ha participado de la 
celebración del contrato, pero indirectamente es receptor de sus efectos de manera positiva.

El tercero expuesto, por su parte, es quien está expuesto -valga la redundancia- de cualquier manera, a una relación de consumo, es decir, se ve afectado por ella. Por ejemplo, si por culpa de una información insuficiente y defectuosa, un museo adquiere un desinfectante para manos que resulta no ser adecuado y, luego, un visitante del museo lo utiliza y su piel se irrita, podría reclamar ante la empresa vendedora del producto.

Como puede notarse, estos últimos dos supuestos cambian el paradigma del derecho civil y comercial ya que otorgan legitimación para reclamar por los daños surgidos de un contrato a un sujeto que no ha sido parte del respectivo pacto.

En cuanto al proveedor, es decir, la contracara del consumidor o usuario, es toda persona humana o jurídica que actúa profesionalmente en el mercado ofreciendo bienes y servicios. Una excepción a esta definición son las profesiones liberales "que requieran para su ejercicio título universitario y matrícula otorgada por colegios profesionales reconocidos oficialmente o por autoridad facultada para ello" (artículo 2, ley $\mathrm{n}^{\mathrm{o}} 24240$ ).

\section{INTERPRETACIÓN A FAVOR DE LOS CONSUMIDORES}

En las páginas iniciales, he explicado que el nuevo Código Civil y Comercial caracteriza a la persona por su dignidad e inviolabilidad, además de autonomía. Estas características se presentan como principios interpretativos ya que, en contraste con el Código Civil anterior, la concepción es más bien sustantiva y no se trata ya de ver en la persona un centro de imputación normativa. Así, pensar al ser humano como consumidor o usuario propone la existencia de barreras infranqueables que los contratos no pueden avasallar y que, pueden incluso significar cargas activas para el Estado a la hora de garantizar el trato digno.

En ese marco, el CCyC, establece en particular que, los proveedores deben garantizar condiciones de atención y trato digno a los consumidores y usuarios. La dignidad de la persona debe ser respetada conforme a los criterios generales que surgen de los tratados de derechos humanos. Los proveedores deben abstenerse de desplegar conductas que coloquen a los consumidores en situaciones vergonzantes, vejatorias o intimidatorias (art. 1097). Si bien estos términos son sumamente amplios e indeterminados, al menos dan cuenta de la imposibilidad de pactar cualquier contenido. Este precepto es interesante por cuanto hace una clara remisión a la humanidad del consumidor o usuario. Sin embargo, cabe recordar que la definición no solo refiere a personas humanas sino también jurídicas.

Por otro lado, el CCyC especifica otros principios interpretativos que deben regir las relaciones de consumo. Estos son derivaciones de los que valen para todo tipo de relación jurídica por lo que pareciera que los legisladores han querido hacer un especial énfasis en este marco. Por ejemplo, en el artículo $1098 \mathrm{CCyC}$, se señala que "los proveedores deben dar a los consumidores un trato equitativo y no discriminatorio. No pueden establecer diferencias basadas en pautas contrarias a la garantía constitucional de igualdad, en especial, la de la nacionalidad de los consumidores". Esto pareciera ser lógico aun cuando no se ejerza el rol de consumidor.

En cuanto a la libertad de contratar, esta se da por supuesta, pero se aclara que no puede quedar supeditadas cláusulas que generen alguna limitación como la condición de adquirir simultáneamente otros servicios o productos (artículo 1099 CCyC). Esto es congruente con la idea de brindar la máxima libertad decisoria al consumidor y limitar, a la vez, el beneficio de la parte más fuerte.

Respecto de la interpretación, el artículo 1094 $\mathrm{CCyC}$ establece un principio de análisis al señalar que las normas que los regulan deben ser aplicadas conforme con el principio de protección del consumidor y el de acceso al consumo sustentable. Siempre se debe estar, en caso de duda, por la opción menos gravosa para el consumidor (art. 1095). Esto supone una notable inversión de las tradicionales relaciones económicas civiles y comerciales puesto que, en lugar de partir de la igualdad entre las partes, una resulta más beneficiada mientras que la restante queda excluida del beneficio interpretativo.

Al igual que respecto de los contratos de adhesión, el artículo 1062 CCyC prohíbe 
$\mathrm{y}$ del adherente en el derecho económico argentino

The legal concept of persona and the protected statuses. Consumers and

adherents case in argentine economic law

llevar a cabo una interpretación restrictiva en los contratos de consumo, entendida esta como el apego a la literalidad de los términos utilizados al manifestar la voluntad. Situación similar ocurre con las cláusulas abusivas que se tienen por inexistentes cuando afecten inequitativamente al consumidor alterando en su perjuicio el equilibrio contractual de derechos y obligaciones de ambas partes (artículo $1119 \mathrm{CCyC}$ ). Por otro lado, hay que destacar que una cláusula puede ser declarada abusiva aún si el consumidor ha participado de la negociación y la ha aceptado (artículo 1118 $\mathrm{CCyC}$ ) por lo que la tutela va más allá de la debilidad en la negociación y presupone una tutela concreta, casuística y práctica (que, al fin y al cabo, estará a cargo de los jueces) de orden público. Es decir, no solo se presupone la incapacidad de negociar de una parte, sino que incluso la protección impone un contenido de lo que el individuo no podría haber aceptado.

Finalmente, el CCyC dispone que, cuando se sancionaren nuevas leyes supletorias, estas no serán aplicables a los contratos en curso de ejecución excepto cuando se tratare de normas más favorables al consumidor en relaciones de consumo (art. 7). Esto provoca que la inseguridad que se intenta combatir en los contratos en general, sí exista para el proveedor. A la par de ello, existe el consumidor recibe un beneficio inesperado. Cabe destacar este artículo no establece la prohibición de empeorar la situación del consumidor, sino que permite mejorarla. Ello claramente puede resultar en un resultado inesperado y perjudicial para el proveedor.

\section{CONSIDERACIONES FINALES}

Este trabajo ha partido del concepto jurídico de persona y de la metáfora que existe detrás de él con el fin de enfatizar que este no apunta al ser humano en sí sino a los roles que este ejerce en el plano del derecho. No obstante, ello, en el ordenamiento jurídico argentino, esto no puede significar la aceptación de que el derecho construye lo que es la persona sino que, por el contrario implica repensar cómo adecuar el sistema legal para que este pueda ser interpretado para dar un trato conforme a la dignidad, inviolabilidad y autonomía de los individuos. Se ha comentado que claramente el Código Civil y Comercial adhiere a este paradigma.
Por otro lado, regular a partir de categorías implica agrupar y abstraer características. Tutelar a la persona para garantizar su dignidad, inviolabilidad y autonomía requiere determinar situaciones potencialmente problemáticas, detectar cómo los individuos interpretan sus roles para intervenir desde las mismas normas jurídicas. En ese marco, este trabajo se ha abocado al derecho económico y, dentro de él, a dos clases tuteladas: adherente y consumidor y usuario. Ello bajo la idea de que, como señala Viola, la concepción actual de los derechos se determina a partir de pensar al sujeto no ya como se hacía en la modernidad, es decir, como un portador inherente de derechos sino como un individuo cuyos derechos inherentes deben ser activamente protegidos. Esto no significa la inexistencia de problemas. Como se ha mencionado, categorizar implica dejar de lado otras problemáticas que se encuentran en intersección. Un consumidor no es solo un consumidor, puede ser una madre que compra alimentos para su hijo, que es clienta de un banco que le expide una tarjeta para abonar los productos, es una transeúnte que camina hasta el supermercado expuesta a riesgos, es una posible beneficiaria de un seguro en caso de sufrir un accidente y es empleada, entre otras posibilidades. La protección que se genera a partir de una categoría es relevante a la hora de concretar derechos, pero no puede ser ejercida en abstracto, sino que debe tenerse en cuenta la contextualización para no desvirtuar la respectiva tutela.

Asimismo, es interesante resaltar las consecuencias interpretativas de las disposiciones que regulan los contratos de adhesión y las relaciones de consumo. La autonomía total de una de las partes no se presupone, la literalidad de la expresión de la voluntad no se acepta aún en cláusulas negociadas y aceptadas por la parte consumidora, existen terceros que pueden efectuar reclamos aun cuando no hayan sido parte del contrato, entre otros.

Finalmente, el estudio de la tutela de los consumidores/usuarios y adherentes sirve para mostrar la conjunción de la metáfora de la persona como ejercicio de un rol y la concepción del individuo a ser cuidado por su dignidad, inviolabilidad y autonomía. De esta manera, es quizás una de las instituciones que muestre con mayor claridad este punto. No obstante, la equiparación de las personas jurídicas a 
las humanas en cuanto a su protección como consumidores/usuarios, desordena un tanto esta idea ya que permite pensar que el fundamento de la tutela no es la dignidad del consumidor sino simplemente mejorar el cumplimiento contractual y facilitar las herramientas para la parte en peores condiciones.

\section{FUENTES DE INFORMACIÓN}

\section{Fuentes bibliográficas}

Alpa, Guido (2004). Derecho del consumidor. Lima, Perú: Gaceta Jurídica.

Chantraine, Pierre (1974). Dictionnaire Étimologique de la Langue Grecque. Histoire des mots. Tomo III $(\Lambda-\Pi)$. París, Francia: Ed. Klincksieck-

Constant, Benjamin (1849). De la Liberté des Anciens comparée à celle des Modernes. Ecrits politiques. Gallimard.

Corominas, Joan y Pascual, José (1981). Diccionario Crítico Etimológico Castellano e hispánico. Madrid, España: Gredos S. A.

Di Pietro y Lapieza Elli (1985). Manual de Derecho Romano. Buenos Aires, Argentina: Depalma.

Ernout, Alfred y Meillet, Antoine (2001). Dictionnaire étymologique de la langue latine. Histoire des mots. Correcciones de Jacques André. $4^{\circ}$ ed. Paris, Francia: Editorial Klincksieck.

Farina, Juan (2004). Defensa del consumidor $y$ del usuario. Comentario exegético de la Ley 24.240 y del Decreto reglamentario 1789/94. $3^{\circ}$ ed. Buenos Aires, Argentina: Astrea.

Gelli, María Angélica (2011). Constitución de la Nación Argentina: comentada y concordada. $4^{\text {o }}$ ed. Buenos Aires, Argentina: La Ley.

Gordillo, Agustín (2013). El poder de policía. En Tratado de derecho administrativo y obras selectas. Tomo VIII. Buenos Aires, Argentina: Fundación de Derecho Administrativo.

Kelsen, Hans (1982). Teoría Pura del Derecho. Roberto Vernengo (trad.) Traducción de la segunda edición en alemán. México: Universidad Nacional Autónoma de México. Instituto de Investigaciones Jurídicas.
Lell, Helga (2017) El concepto jurídico de "persona humana" y el acercamiento de la ciencia del derecho. Miranda, L.R. (eds.). Metáfora y episteme: hacia una hermenéutica de las instituciones. Neuquén: Círculo Hermenéutico. Páginas 187-206.

Liddell, Henry George y Scott, Robert (1940). A Greek-English Lexicon. Revisado por Henry Stuart Jones con la colaboración de Roderick McKenzie. Clarendon Press. Publicado por Perseus Project.

Lorenzetti, Ricardo (2003). Consumidores. Santa Fe, Argentina: Rubinzal Culzoni Editores.

Paricio, Javier (2015). Persona: un retorno a los orígenes. Cuena Casas, Matilde, Anguita Villanueva, Luis Antonio y Ortega Doménech, Jorge (coords.). Estudios de derecho civil en Homenaje al profesor Joaquín José Rams Albesa (Páginas 279-292). Madrid, España: Dykinson-

Petit, Eugène (2015). Tratado elemental de Derecho Romano. Traducido de la novena edición francesa y aumentado por José Ferrández González. 23º ed. México, México: Porrúa

Stoddart, Simon K. F. (2009). "Phersu". Historical Dictionary of the Etruscans. Scarecrow Press.

\section{Fuentes hemerográficas}

Arias, César (1969). Con motivo de una controversia sobre la ideología del Código Civil. En Lecciones y Ensayos. Número 40, páginas 11-26.

Berlin, Isaiah (1969). Two concepts of liberty. Four Essays On Liberty. Oxford: Oxford University Press, pp. 118-172. Blanch de Nogues, José María (2007). Sobre la personalidad de las "Fundaciones" en Derecho Romano. Revista Jurídica de la Universidad Autónoma de Madrid. Núm. 16, páginas. 9-28.

Blanch de Nogues, José María (2007). Sobre la personalidad de las "Fundaciones" en Derecho Romano. En Revista Jurídica de la Universidad Autónoma de Madrid. Núm. 16. Páginas 9-28. 
The legal concept of persona and the protected statuses. Consumers and

adherents case in argentine economic law

Cabrera Peña, Karen Isabel (2011). El derecho de consumo desde la teoría clásica del contrato hasta los nuevos contratos. En Revista de derecho: División de Ciencias Jurídicas de la Universidad del Norte. $\mathrm{N}^{\circ}$. 35, 2011. Páginas 55-95.

Durand, Julio (2005). Sobre los conceptos de "policía", "poder de policía" y "actividad de policía". En Revista de Derecho Administrativo, $\mathrm{N}^{\circ}$ 51, Buenos Aires, Lexis Nexis.

Garzino, María Constanza (2005) La influencia de los tratados internacionales en el derecho del consumidor argentino. En Anuario de derecho civil. Vol. 10. Argentina: Universidad Católica de Córdoba.

Lell, Helga (2018). El concepto de persona humana en el sistema jurídico interamericano. En Letra. Año V, No 10. páginas 116-133.
Monge, Natalia (2017). Derecho de propiedad y crisis económica. En Revista Cartapacio de Derecho, Facultad de Derecho. Vol. 31 (2017). UNICEN.

Néndoncelle, Maurice (1948). Prósopon et persona dans l'antiquité classique. Essai de bilan lingüistique. En Revue des Sciences Religieuses. Tomo 22, Fascículo 3-4. Páginas 277-299

Viola, Francesco (2015). El estatuto jurídico de la persona. En Derecho y cambio social. $\mathrm{N}^{\circ}$ 40 Año XII. Páginas 1-20. 